\title{
O professor iniciante da educação básica: uma reflexão sobre seus desafios e aprendizados
}

\author{
Maria Célia Borges \\ Universidade Federal de Uberlândia - UFU, Brasil \\ Paulo Vinicius dos Santos \\ Universidade Federal de Uberlândia - UFU, Brasil
}

\section{RESUMO}

O presente trabalho tem como objetivo conhecer quem é o professor iniciante dos primeiros anos do ensino fundamental da escola pública e quais são os desafios e aprendizados no seu desenvolvimento profissional. Procura-se analisar e compreender os desafios e as aprendizagens do professor iniciante no âmbito escolar, bem como a receptividade que a escola propicia a estes profissionais neste período de descobertas e de crises advindas da formação profissional, momento em que o professor fica à mercê dos seus dilemas, medos, angústias, inseguranças e incertezas, enquanto professor no início de sua carreira. Portanto, são inúmeros os conflitos e desafios vivenciados. O anseio pela escrita deste trabalho foi desencadeado durante a primeira experiência no magistério e pelas observações durante os estágios propiciados pela Universidade Federal de Uberlândia. Ressalta-se que este artigo retrata a realidade de uma escola municipal próxima à cidade de Ituiutaba-MG. Para esta análise, optouse por uma pesquisa de abordagem qualitativa, englobando pesquisa bibliográfica, documental e de campo. Os principais autores que deram sustentação a este trabalho foram Huberman (1992); Cavaco (1995); Franco (2000); Imbernón (2004); Garcia (2010) dentre outros, que problematizam esta discussão. Os procedimentos de coleta de dados incluíram a aplicação de entrevistas e a observação. Buscou-se, de forma clara e audaciosa, refletir sobre o ingresso nesta profissão que é marcada por inúmeras crises que, posteriormente, podem refletir no trabalho profissional. Desafiou-se, também, o professor iniciante a indagar as teorias antes defendidas e/ou estudadas na Universidade, confrontando-as com as primeiras experiências no magistério, no cotidiano escolar. O ensejo foi trazer uma contribuição desencadeadora de reflexões sobre a formação do professor, o acolhimento e o apoio necessários no início de sua carreira docente.

PALAVRAS-CHAVE: Professor Iniciante. Desafios e conflitos. Aprendizados.

\section{THE BEGINNING TEACHER OF ELEMENTARY SCHOOL: A REFLECTION ON THEIR CHALLENGES AND LEARNINGS}

\begin{abstract}
The present work aims to know who is the beginning teacher of the first years of elementary school public school and what are the challenges and learning in their professional development. It seeks to analyze and understand the challenges and the learning of the beginning teacher in the school environment, as well as the receptivity that the school provides to these professionals in this period of discoveries and crises arising from professional training, at which point the teacher is at the mercy of his dilemmas, fears, anguish, insecurities and uncertainties as a teacher at the beginning of his career. therefore, There are many conflicts and challenges experienced. the yearning for the writing of this work
\end{abstract}


was triggered during the first experience in teaching and by the observations during the stages offered by the Federal University of Uberlândia. It is emphasized that this article portrays the reality of a municipal school near the city of Ituiutaba-MG. For this analysis, a qualitative research was chosen, encompassing bibliographical, documentary and field research. The main authors who gave support to this work were Huberman (1992); Cavaco (1995); Franco (2000); Imbernón (2004); Garcia (2010), among others, who problematize this discussion. Data collection procedures included the application of interviews and observation. It was sought, in a clear and audacious way, to reflect on the entrance in this profession that is marked by innumerable crises that, later, can reflect in the professional work. it was also challenged the beginner teacher to investigate the theories previously defended and / or studied in the university, confronting them with the first experiences in teaching, in the daily school life. The occasion was to bring a contribution triggering reflections on teacher education, the reception and support needed at the beginning of his teaching career.

KEYWORDS: Beginning teacher. Challenges and conflicts. Learning.

\section{EL PROFESOR INICIANTE DE LA EDUCACIÓN BÁSICA: UNA REFLEXIÓN SOBRE SUS DESAFÍOS Y APRENDIZAJES}

\section{RESUMEN}

El presente trabajo tiene como objetivo conocer quién es el profesor principiante de los primeros años de la enseñanza fundamental de la escuela pública y cuáles son los desafíos y aprendizajes en su desarrollo profesional. Se busca analizar y comprender los desafíos y los aprendizajes del profesor principiante en el ámbito escolar, así como la receptividad que la escuela propicia a estos profesionales en este período de descubrimientos y de crisis provenientes de la formación profesional, momento en que el profesor queda a merced de los mismos sus dilemas, miedos, angustias, inseguridades e incertidumbres, como profesor al inicio de su carrera. Por lo tanto, son innumerables los conflictos y desafíos vivenciados. El anhelo por la escritura de este trabajo fue desencadenado durante la primera experiencia en el magisterio y las observaciones durante las etapas propiciadas por la Universidad Federal de Uberlandia. Se resalta que este artículo retrata la realidad de una escuela municipal cercana a la ciudad de Ituiutaba-MG. Para este análisis, se optó por una investigación de abordaje cualitativo, englobando investigación bibliográfica, documental y de campo. Los principales autores que dieron sustento a este trabajo fueron Huberman (1992); Cavaco (1995); Franco (2000); Imbernón (2004); García (2010) entre otros, que problematizan esta discusión. Los procedimientos de recolección de datos incluyeron la aplicación de entrevistas y la observación. Se buscó, de forma clara y audaz, reflexionar sobre el ingreso en esta profesión que está marcada por innumerables crisis que, posteriormente, pueden reflejar en el trabajo profesional. Se desafió, también, al profesor principiante a indagar las teorías antes defendidas y / o estudiadas en la Universidad, confrontándolas con las primeras experiencias en el magisterio, en el cotidiano escolar. La ocasión fue traer una contribución desencadenante de reflexiones sobre la formación del profesor, la acogida y el apoyo necesarios al inicio de su carrera docente.

PALABRAS CLAVE: Profesor principiante. Desafíos y conflictos. El aprendizaje.

\section{INTRODUÇÃO}

A motivação da construção deste trabalho, composto por investigação e sínteses dos resultados aqui apresentados, é oriunda do desejo e da busca de conhecimentos, como também 
de conflitos ocasionados pela condição do segundo autor de recém-graduado e de professor regente iniciante no Ensino Fundamental, em uma escola pública municipal próxima à cidade de Ituiutaba, e pelas observações durante os estágios propiciados pela Universidade Federal de Uberlândia. Na condição de professor estreante, vivenciamos diversos desafios marcados por inúmeros conflitos, incertezas, medos, angústias e aprendizagens ao longo do ano letivo de 2014.

Destarte, esta investigação tem como objetivo analisar e compreender os desafios e as aprendizagens do professor iniciante no âmbito escolar que foram e são marcados por inúmeras crises e momentos conflituosos enfrentados no início de sua carreira, pois, segundo Souza (2009, p. 01) “[...] de modo geral, o início da carreira constitui um período marcado por crises”.

A pesquisa apresenta relevância científica, social e cultural, pois poderá contribuir para os graduandos dos cursos de Licenciatura, para as análises sobre os impactos ocasionados no trabalho deste professor iniciante, além de impulsionar discursos e observações diante desta primeira experiência na carreira docente.

Analisamos a receptividade que a escola propicia a este profissional neste período de descobertas e de crises advindas da sua formação profissional, momento em que o professor fica à mercê dos seus dilemas, medos, anseios, angústias, inseguranças e incertezas enquanto professor iniciante. Tardif $(2002$, p.84) salienta sobre o início da carreira como “[...] um período muito importante da história profissional do professor, determinando inclusive seu futuro e sua relação com o trabalho".

A formação do professor ocorre em um continuum porque, como sujeito, ele não cessa de aprender, o que vai ao encontro de Paulo Freire (1996, p. 25): “[...] quem ensina aprende ao ensinar e quem aprende ensina ao aprender".

\section{REFERENCIAL TEÓRICO}

A fundamentação teórica de nosso trabalho se fundamenta em teorias produzidas pelos principais autores e estudiosos da área, tais como: Huberman (1992); Cavaco (1995); Franco (2000); Imbernón (2004); Garcia (2010), dentre outros. Buscamos fundamentos selecionando e explorando artigos, dissertações, pesquisas e trabalhos científicos acerca do tema com vistas à construção de referencial teórico pertinente, que pudesse dar sustentação científica à pesquisa.

De modo geral, o começo da carreira do professor iniciante é marcado por inúmeros desafios, conflitos e várias crises, pois este é o momento no qual o graduando/estudante sai de sua estabilidade como aluno e emerge na carreira, sendo visto como um ser preparado para atuar diante dos obstáculos, desafios e divergências apresentadas em nosso cotidiano na sala de 
BORGES, M. C..; SANTOS, P. V.

aula. Diante de tais colocações, vale citar Garcia (2010, p. 8) que, sobre o período de transição, sintetiza:

A construção da identidade profissional se inicia durante o período de estudante nas escolas, mas se consolida logo na formação inicial e se prolonga durante todo o seu exercício profissional. Essa identidade não surge automaticamente como resultado da titulação, ao contrário, é preciso construíla e modelá-la.

Também Franco (2000, p. 33), corroborando com Marcelo Garcia (2010), afirma que "[...] o início da carreira docente tem sido para muitos professores um período difícil, no qual vários problemas se evidenciam", pois é neste período que o indivíduo faz o processo de transição entre ser aluno e se tornar professor. Essa fase representa embate e desafio, o que comumente ocasiona inúmeros desconfortos e conflitos a este profissional.

Notamos que muitas vezes os professores, ao ingressarem na carreira docente, encontram dificuldades para atuar. Estas variam desde a forma como eles se comportam, até com relação ao domínio de conteúdo, pois muitas vezes, o professor iniciante se encontra muito inseguro e com dificuldades, conforme ressalta Garcia (2010, p. 17) "É um período de tensões e aprendizagens intensivas em contextos geralmente desconhecidos e durante o qual os professores iniciantes devem adquirir conhecimento profissional, além de conseguirem manter certo equilíbrio pessoal". Sabemos que isto prejudica, certamente, a construção da autonomia do profissional docente.

Insegurança, sobrevivência, adaptações, conformismo, medos, angústias, solidão e incertezas são alguns dos sentimentos mais comuns nos professores iniciantes ao começarem sua carreira docente, no âmbito escolar e, posteriormente, na sala de aula. Parece haver um conflito visto como um processo de responsabilização de tamanha fecundação que "[...] o professor pode ser levado a reatualizar experiências vividas como aluno", conforme pontua Cavaco (1995, p.164) e pode até se esquecer dos conhecimentos adquiridos na formação inicial.

Essa "fase" ou "ciclo" do processo de inserção do professor, como iniciante ou ingressante na carreira, geralmente ocorre dessa forma nos primeiros anos, pois há um processo de transição da fase que passa a ser vista como uma categoria situacional, ou seja, de "situação", conforme afirma Souza (2009, p.36): “[...] o professor deixa de ser "iniciante”, pois o predicativo iniciante refere-se a uma categoria transitória e situacional".

Este profissional é colocado no âmbito escolar e posto à prova de seus conhecimentos acumulados ao longo do seu processo de graduação. De outro modo, pode ser visto como "refém" diante de um sistema que comumente encontra-se arcaico e tradicional. Torna-se importante destacar o que salienta Huberman (1992, p. 38): “[...] o desenvolvimento de uma carreira é, assim, um processo e não uma série de acontecimentos". 
Normalmente este indivíduo sente-se desamparado e sem nenhum suporte diante de suas angústias e, algumas vezes, é obrigado a enfrentar as barreiras sozinho, sem encontrar nenhum auxílio que necessita e deseja, pois, conforme Garcia (2010, p. 5) "Os mestres e professores, geralmente, enfrentam sozinhos a tarefa de ensinar. Somente os alunos são testemunhas da atuação profissional dos docentes. Poucas profissões se caracterizam por uma maior solidão e isolamento".

Há de se registrar que também não existem, em nosso contexto, programas de acompanhamento dos egressos dos cursos de Licenciaturas, como não há, também, um projeto de apoio aos professores iniciantes nas escolas ou Secretarias de Educação.

Nestas circunstâncias, o professor iniciante procura em outros espaços, que não sejam o espaço escolar, informações alternativas como "ideias", "refúgios" e "caminhos", imbuído do temor de ser mal visto e observado pelos demais profissionais como "fracassado". Fortalecemos esta perspectiva fundamentados na teoria de Cavaco (1995, p.167) que, com total nitidez, afirma que por não encontrarem esse apoio, os professores "sentem necessidade de recorrer às redes informais de apoio (...) e, na maioria das vezes, fora da escola porque na escola se teme o descrédito que a confissão das dificuldades e o pedido de auxílio pode provocar".

A respeito dessa discussão Brostolin e Oliveira (2013, p. 47) destacam a "busca" por ajuda deste professor principiante, afirmando que:

Durante o processo de formação, o acadêmico pode contar com a colaboração dos professores e colegas de graduação, diferentemente do que ocorre na prática dentro das escolas, onde o já professor se vê sozinho, enfrentando os desafios e os dissabores da profissão sem a ajuda necessária para seu desempenho satisfatório.

Nesse sentido, deveria haver um projeto na Universidade para acompanhar os egressos no início de carreira. Na busca de maior conexão entre a formação na universidade e as experiências de campo na formação de professores em Instituições de Educação Superior (IES), onde se formam os futuros professores, aparece o conceito de "terceiro espaço" que propõe:

[...] a criação de espaços híbridos nos programas de formação inicial de professores que reúnem professores da Educação Básica e do Ensino Superior, e conhecimento prático profissional e acadêmico em novas formas para aprimorar a aprendizagem dos futuros professores. Contrários à desconexão tradicional entre escola e universidade e à valorização do conhecimento acadêmico como a fonte de autoridade do conhecimento para a aprendizagem sobre o ensino, próprio dos modelos tradicionais de formação de professores das escolas normais superiores e das universidades (SMAGORINSKY, COOK e JOHNSON, 2003), os terceiros espaços reúnem o conhecimento prático ao acadêmico de modos menos hierárquicos, tendo em vista a criação de novas oportunidades de aprendizagem para professores em formação. (ZEICHNER, 2010, p. 486). 
Esses espaços híbridos - ou "terceiro espaço" incentivam um status mais democrático e direto para seus participantes: os professores das Universidades, os licenciandos e os professores da Educação Básica. São espaços de busca de transformação e inovação da formação docente, possibilitando maior oportunidade para o aprendizado ampliado e significativo. Nesse contexto coexistem a possibilidade de formação inicial e formação continuada.

Zeichner (2010) ainda complementa essa ideia afirmando que a criação de espaços híbridos na formação de professores onde o conhecimento empírico e o acadêmico, somados ao conhecimento existente nas comunidades, estão juntos de modos menos hierárquicos a serviço da aprendizagem docente e, desse modo, representa mudanças de paradigma na epistemologia dos programas de formação de professores. Ainda nesse prisma, o mesmo autor afirma que as pesquisas têm demonstrado claramente que as experiências de campo constituem importantes ocasiões para que se efetive a aprendizagem docente mais do que meramente momentos nos quais os futuros professores podem demonstrar ou aplicar coisas previamente aprendidas.

Nessa perspectiva, a nova lógica de organização curricular para a formação de professores, tais como os ciclos de aprendizagem, a interdisciplinaridade e os currículos devem estar articulados com as escolas-campo de trabalho dos professores e ao estágio e devem fazer um trabalho conjunto e rico de aprendizados para todos os envolvidos. (PIMENTA, 2005). Colocamos, como exemplo deste terceiro espaço de formação, o PIBID, que no Brasil é um programa subsidiado pela CAPES.

Entretanto, voltando para a realidade do profissional que está iniciando sua carreira, é comumente possível notar que, muitas vezes, ele é colocado em turmas difíceis, com alunos heterogêneos e, ainda, é recebido com forte resistência por parte dos "colegas" de trabalho, nesse contexto, pelos professores que há mais tempo foram inseridos no âmbito escolar e que são vistos como “veteranos" e "experientes”. Conforme salienta Guarnieri (1996, p.15) “[...] os veteranos, entretanto, usualmente obtêm atribuições de ensino mais atraentes e com alunos mais capazes".

A falta de diálogo existente entre os professores e a gestão na escola, somados à falta de apoio e respeito pelo professor iniciante, pode gerar um mal-estar logo no início. Esta questão, segundo Morais (2012) está causando o aumento dos distúrbios psíquicos e as somatizações ocasionados pelas dramáticas relações interpessoais nos segmentos intermediários, não só entre professores e alunos. Existe, também, o "burocrativismo administrativo que não logra se elevar ao nível de gestão educacional" (p. 85) e que "[...] submete o professorado ao que temos de 
mais medíocre no âmbito da ética do interesse (funcionalidade do lucro)" (p.86). No contexto acadêmico, raramente a "minoria" não sucumbe às pesadas pressões da "maioria cognitiva", sendo conduzida a avaliar negativamente a relação entre o seu trabalho e os resultados dele. Assim, a maioria cognitiva desestabiliza o tônus emocional do docente, causando-lhe confusão íntima e desgaste, seguido de stress existencial. Além disso, pode acontecer de os docentes comumente sofrerem graves ameaças de seus alunos que, lamentavelmente, formulam a conduta do docente por este temê-los e sentir-se pressionado.

Quanto às aprendizagens construídas ao longo do seu processo de inserção na carreira docente, Vieira (2013 p. 29) sintetiza:

Nesse particular, o novato, mesmo envolto às dificuldades perante as quais se defronta no desenvolvimento de sua atividade, vai construindo seus saberes e, talvez mesmo, a partir delas. Ou seja, estes sentimentos de angústia; insegurança; ansiedade podem impulsionar as aprendizagens significativas, uma vez que desequilibram, estimulam as tomadas de decisão.

Em consideração às colocações do autor, é possível percebermos, que mesmo diante das dificuldades, medos, inseguranças e ansiedade do início da carreira docente, os desafios poderão contribuir para sua aprendizagem e aquisição de conhecimentos.

Ainda sobre os aprendizados dos professores, Pimenta e Anastasiou (2005) elencam os principais saberes para o exercício da profissão docente. Dentre eles podem ser destacados os saberes da experiência, que relatam o modo como nos apropriamos do ser professor em nossa vida, nas experiências do cotidiano da sala de aula, como aluno ou como professor; os saberes da área do conhecimento, relacionados aos conhecimentos específicos, conhecimentos científicos, resultantes dos estudos, leituras, cursos, dentre outros. É preciso ter domínio do conteúdo, pois ninguém ensina o que não sabe. Este domínio também deve englobar os saberes pedagógicos, responsáveis por pensar o ensino como uma prática educativa, com diferentes e diversas direções de sentido na formação do ser humano. Deve incluir, também, a gestão da classe, o relacionamento com os educandos, as estratégias de ensino vivas, dinâmicas, prazerosas e efetivas, bem como os saberes didáticos, responsáveis pela articulação da teoria da educação e da teoria de ensino para ensinar nas situações contextualizadas e realizar a práxis pedagógica.

Desta maneira, percebemos que o professor - especialmente o professor iniciante aprende o tempo todo com os estudos, com as experiências, com os desafios enfrentados e, mediante a reflexão sobre os erros e os acertos com os quais se defronta no seu dia-a-dia na sala de aula. 
Por conseguinte, segundo Huberman (1992) há fases perceptíveis que acompanham a carreira do professor que permeiam e marcam seu trabalho em várias formas e aspectos que, possivelmente, determinarão suas ações e sua posição profissional.

Em seguida, fazemos uma breve apresentação destas fases, pois as consideramos importantes neste trabalho para fortalecer ideias e desencadear discussões diante de tal perspectiva.

a) "A entrada na carreira" é vista como a primeira fase retratada pela "descoberta", na qual o professor iniciante percebe-se em um processo de experimentação, de responsabilização. A responsabilidade de ter sua turma, o sentimento de parte de um grupo de profissionais de uma determinada área. Neste período experiência o novo e muitas descobertas e aprendizagens. Porém, esta fase atrela-se a outra perspectiva: a de "sobrevivência", que se traduz como choque de realidade/choque real; pois se depara com circunstâncias, dificuldades e do abismo/lacuna entre o ideal e o real (teoria x prática). Esse contexto sofrido pois, comumente, não conseguem fazer a práxis, ou a junção entre os fundamentos estudados enquanto graduando, e ação pedagógica na sala de aula, no início da profissão docente. É comum a insegurança quanto ao domínio do conteúdo e o ínfimo manejo para a gestão da classe, o que acarreta, como consequência, a indisciplina dos alunos. O que mantém este professor "firme" e "marcado pelos impactos" da sobrevivência é o que salienta Huberman (1992, p. 39) "[...] o da sobrevivência e o da descoberta, são vividos em paralelo e é o segundo aspecto que permite aguentar o primeiro".

b) “A fase de estabilização" é o processo por meio do qual o professor iniciante se estabiliza no âmbito escolar ao sentir-se parte de um grupo de profissionais e com independência, ou melhor, o que seria, segundo Huberman (1992, p. 40) “[...] estabilizar significa acentuar o seu grau de liberdade, as suas prerrogativas, o seu modo de funcionamento".

c) "A fase de diversificação" é caracterizada pelo fato destes professores serem os mais dinâmicos, motivados ou os que se mantêm mais dispostos em busca de desafios, conforme explicita Huberman (1992, p. 42) "[...] o professor parte em busca de desafios".

d) "Pôr- se em questão", fase vista como uma vivência contraditória, pois o que antes era diversificado, ou como dinâmico pelo professor começa a ser visto como algo monótono e alguns questionamentos são feitos por este profissional, tais como, sua postura e seu papel. Segundo o autor, mesmo esta fase é vista, provavelmente, como "desencanto" da profissão. (HUBERMAN, 1992, p. 43)

e) "Serenidade e distanciamento afetivo" - se outrora este profissional exibia um ótimo entrelaçamento de serenidade e afetividade, nesta fase o professor apresenta-se com 
questionamentos e ausência deste sentimento, pois se apresentam, segundo o autor, "menos sensíveis, ou menos vulneráveis”. (HUBERMAN, 1992, p. 44)

e) "Conservantismo e lamentações" é o momento em que os professores se queixam do comportamento dos alunos e de suas atitudes, pois julgam suas concepções e suas formas de agir por acreditarem no seu conservadorismo como algo tido como "imutável”, "certo", ou até mesmo, como um "dogma". Afinal, tudo que foge de seus costumes e ideias é considerado errado e criticado por eles, ou seja, são tradicionais quanto à evolução da escola e de seus indivíduos.

f) "O desinvestimento" - se antes este profissional era dinâmico, motivador e interativo, nesta nova fase ele se encontra, digamos, menos "ambicioso", pois acredita que já não há mais razões para fazer tanta mudança no ensino. Este perfil poderá ser visto como uma "modalidade", "fase" ou "ciclo" dos professores que estão em fim de carreira, porém, ressalta-se que estamos tratando de "momentos", "fases" ou "ciclos" da carreira docente, pois conforme cita o autor HUBERMAN (1992, p. 46) “[...] uma vez que se trata do desenvolvimento de tendências já manifestas".

Neste estudo damos maior ênfase à primeira fase denominada "entrada na carreira", pois ela sintetiza o foco central da discussão objeto desta investigação.

Diante da discussão de tais "ciclos" e/ou "fases" analisadas que compõem o processo de carreira do professor, há inúmeras divergências que podem variar conforme a cultura e o local onde este profissional atua. Não tratamos aqui de algo tido como "verdade indiscutível", mas como um percurso na carreira entendido como um processo que vai sendo construído ao longo do tempo.

Corroborando com a ideia acima, Freitas (2002, p.156) afirma que “[...] é necessário levar em conta tanto a história do professor iniciante, suas expectativas e projetos quanto as características do grupo profissional a que irá pertencer". Afinal, a dificuldade pode variar de indivíduo para indivíduo, de profissional para profissional e de docente para docente, pois o processo de inserção na docência aparecerá de diferentes formas, por meio de relatos e experiências.

Por fim, as experiências vivenciadas pelo profissional docente desde o início de sua carreira, bem como a sua formação inicial e continuada, vão contribuindo para a construção dos saberes teóricos e práticos, ou ainda, segundo Pimenta (2005) saberes do conhecimento, saberes experienciais e saberes pedagógicos, os quais vão se somando e contribuindo para a formação da identidade do professor. 
BORGES, M. C..; SANTOS, P. V.

\section{METODOLOGIA}

Com relação aos procedimentos metodológicos, a pesquisa em pauta é de cunho qualitativo, dentro de uma vertente crítica. Nesse sentido, as reflexões e análises da pesquisa são orientadas pela concepção filosófica dentro de uma visão crítica. Para tanto, tomamos a educação como práxis construtora da história, atentando para a dimensão política da prática pedagógica. Optamos por uma abordagem qualitativa, contando com pesquisa bibliográfica, documental e de campo. Os procedimentos de coleta de dados incluem a aplicação de questionário e a observação.

Segundo Minayo (2007, p. 21) "a pesquisa qualitativa responde a questões muito particulares [...] Ela trabalha com um universo dos significados, dos motivos, das aspirações, das crenças, dos valores e das atitudes".

Inicialmente foi realizada uma pesquisa bibliográfica buscando conhecer a situação atual do tema-problema, especialmente os desafios do professor iniciante. Para o embasamento teórico buscamos subsídios em artigos, teses, dissertações, livros, dentre outros.

Em seguida, foi elaborado e aplicado um questionário utilizando um roteiro contendo questões abertas e fechadas. Selecionamos, por amostragem, os professores iniciantes, totalizando oito sujeitos depoentes. Os escolhidos foram os atores na vivência, tais como iniciantes do magistério, que experimentam todas as incertezas e angústias desse processo.

A seleção da amostra foi orientada por Fontanella; Ricas e Turato (2009) afirmam que numa amostragem o importante não é quantos, mas quem será entrevistado, uma vez que a pesquisa é qualitativa. Assim, o importante é a maneira como se concebe a representatividade desses elementos e a qualidade das informações obtidas.

As questões do questionário indagavam aos informantes sobre seus desafios e incertezas quanto à sua própria formação. Porém, é importante salientar que apresentaram, também, aprendizados de ressignificação diante de sua formação, bem como amadurecimento diante das dificuldades.

O questionário foi um recurso utilizado e que muito colaborou com a confirmação da fundamentação teórica e para as respostas à problemática apresentada inicialmente. Tal questionário encontra-se anexado neste trabalho e contém 18 perguntas, sendo 13 abertas e cinco fechadas que, em sua essência, tratam desde perguntas pessoais a perguntas profissionais, em consonância com o objetivo geral desta investigação, qual seja: conhecer quem é o professor iniciante dos primeiros anos do ensino fundamental da escola pública, e quais são seus desafios e aprendizados no seu desenvolvimento profissional. 
Assim, para o delineamento da pesquisa quanto ao uso do questionário, nos apoiamos em Dalberio, Borges (2014) que afirmam que “[...] o questionário é um recurso para obtenção de dados, largamente utilizado em pesquisas nas mais variadas áreas do conhecimento e, em especial, nas ciências humanas e sociais".

Foram entregues os questionários a oito professores de uma escola municipal e foi dado a eles tempo suficiente para respondê-los. O critério de seleção foi o de iniciantes na carreira docente, uma vez que todos tinham até dois anos de experiência no magistério. Salienta-se que os profissionais foram bastante receptivos e se dispuseram a participar da pesquisa de forma positiva e harmoniosa.

Com o intuito de propiciar melhorias no campo da pesquisa tendo como aparato um referencial teórico crítico, fundamentamos e analisamos atentamente as perguntas para que pudéssemos obter os dados precisos para interpretação.

\section{APRESENTAÇÃO E ANÁLISE DOS RESULTADOS}

Em consideração aos objetivos deste trabalho, propomo-nos a fazer uma exposição breve dos dados e resultados obtidos conforme suscitamos no objetivo geral, o qual consiste em conhecer quem é o professor iniciante dos primeiros anos do ensino fundamental da escola pública e quais são os desafios, conflitos e aprendizados vivenciados no seu desenvolvimento profissional.

Diante de tal fundamentação e análise, salientamos que os dados foram apresentados, interpretados, analisados e, por fim, relacionados ao referencial teórico proposto como forma de discussão.

Esta discussão foi dividida em três etapas nas quais descrevemos, separadamente, os seguintes momentos: preliminarmente, descrevemos o perfil destes profissionais dos primeiros anos do ensino fundamental; no segundo momento apresentamos os desafios e conflitos que os docentes comumente encontram quando ocorre a inserção na carreira docente; e, por último, apontamos as aprendizagens atribuídas neste contato inicial de entrada no âmbito escolar.

Diante do exposto, podemos elencar três categorias de discussão, quais sejam:

1) o perfil destes profissionais nos primeiros anos do ensino fundamental;

2) os desafios vivenciados pelos docentes no processo de inserção na carreira docente;

3) as aprendizagens atribuídas neste contato inicial.

Para os dados de investigação e perfil destes profissionais nos primeiros anos do ensino fundamental, foram consideradas oito professoras iniciantes (Ana Emília, Pilar, Alícia, Laís, 
BORGES, M. C..; SANTOS, P. V.

Marcela, Elisa, Rafaela e Agnes) ${ }^{1}$, sendo que todas elas pertencem a uma rede municipal de ensino. A caracterização das professoras foi feita por meio do questionário que contou com seis questões de caracterização do perfil profissional.

Com base nos dados, é possível afirmar que o quadro de professores desta rede municipal de ensino é composto, por sua maioria, ou quase na sua totalidade, por mulheres, conforme exemplifica Gabardo e Hobold (2011, p. 92): “A docência, apesar de ter tido sua origem ministrada por homens, atualmente é consenso a constatação da grande presença feminina nesta área, principalmente nos anos iniciais do ensino fundamental”.

\subsection{Perfil dos sujeitos}

Com relação ao perfil dos sujeitos colaboradores da pesquisa, constatou-se que a faixa etária das participantes varia entre vinte e dois e trinta e sete anos, com estado civil diversificado (casadas, solteiras e/ou divorciadas), definidas como brancas ou pardas (cor/raça/etnia) e residem no mesmo estado (Minas Gerais) e, particularmente, atuam no mesmo município.

As professoras atuam nas séries iniciais do Ensino Fundamental, mais precisamente do $2^{\circ}$ ano ao $5^{\circ}$ ano, sendo que seis delas possuem graduação em Licenciatura Plena em Pedagogia e duas são graduandas do Curso de Pedagogia. Ressalta-se que das oito professoras que responderam ao questionário, cinco delas (Ana Emília, Alícia, Laís, Marcela e Agnes) graduaram-se em uma instituição privada, uma (Elisa) graduou-se numa instituição pública e as outras duas (Pilar e Rafaela) são estudantes do curso de Pedagogia.

Com relação às horas dedicadas à docência, semanalmente, pode-se perceber uma divergência. Entretanto, é possível fazer uma demarcação de tempo/horário. Apenas a professora Alícia disse se dedicar mais de oito horas por semana à docência. Já as professoras Ana Emília, Marcela, Elisa e Laís disseram que se dedicam entre oito e dezoito horas, enquanto as professoras Agnes e Rafaela afirmaram dedicar-se de trinta a quarenta horas semanais. Em análise desta dedicação semanal, verifica-se que ela está atrelada às preocupações do professor iniciante devido à insegurança e medo, que fazem com que ele se dedique ainda mais por acreditar que precisa se aperfeiçoar e/ou mudar, ou ainda, "melhorar" enquanto profissional, ao considerar suas dificuldades. Complementando esta colocação, citamos a fala da professora Elisa que afirma: “É um tempo que acho importante para fazer as atividades com relevância e com dedicação pelo material que se vai levar ao seu aluno e consigo mesmo na hora de aprimorar seus conhecimentos para dividir com eles na sala de aula".

\footnotetext{
${ }^{1}$ Nomes fictícios.
} 
Em relação à questão salarial, todas as oito professoras disseram que sua faixa salarial gira em torno de dois salários mínimos, - algumas vezes menos -, o que pode ser considerado como "um dos atributos" para desistência da carreira, conforme apresenta Garcia (2010, p. 10):

Hoje em dia, pelo contrário, o trabalho docente tem sido qualificado como um trabalho de risco, participando de quase todos os fatores considerados habitualmente como fonte de fadiga nervosa: sobrecarga de tarefas, baixo reconhecimento, atenção a outras pessoas, papel ambíguo, incerteza em relação à função, falta de participação nas decisões que lhe são concernentes, individualismo e impotência.

Salientamos que todas as professoras trabalham/atuam apenas em uma instituição educacional pelo simples fato da imensa responsabilidade para se "desdobrar" como docentes, conforme podemos citar o posicionamento das professoras Ana Emília e Agnes. Ao serem questionadas se precisavam trabalhar em outra área, elas foram breves em suas colocações, em que a primeira (Ana Emília) informou já ter trabalhado em um projeto anterior e a segunda (Agnes) disse que não havia tempo suficiente para trabalhar em outra área, conforme explicita: "este ano não estou trabalhando dois períodos, mas ano passado trabalhei no Projeto Cantinho Amigo”. Finalmente, destacamos, também, a fala da professora Agnes: "porque na área que escolhi professora, não me sobra tempo para atividades extras ”.

Quanto ao tempo (horas) que elas necessitam para planejar, estudar, corrigir trabalhos e avaliações, houve uma variação no tempo entre três a oito horas, pois, segundo a professora Laís "é o tempo que eu tenho". Nota-se que a cobrança por resultados e pelo trabalho excessivo de material e de afazeres faz com que o professor, algumas vezes, se sinta cansado e angustiado, pois ao ingressar na carreira, o docente sente alto grau de responsabilizações, comum nesta passagem sobre a qual Lima (2004, p.84) afirma "passagem de estudante a professor".

\subsection{Desafios da carreira}

Neste segundo momento pudemos identificar como são inúmeros os desafios dos docentes ao se inserirem na carreira profissional, conforme destaca Cavaco (1995, p. 162) “[...] o início da atividade profissional é, para todos os indivíduos, um período contraditório".

Ressalta-se que o tempo de atuação das professoras varia de poucos meses a dois anos, pois, conforme salientamos acima, o objetivo de nossa pesquisa foi entrevistar e conhecer professores com, no máximo, dois anos de prática profissional na docência. A escolha é justificada por ser neste período que as inúmeras crises são evidenciadas e marcadas, conforme salienta Montalvão (2008, p. 24): “[...] o início da atividade profissional é o período que abrange os primeiros anos de docência". 
Em análise e observação aos questionários preenchidos pelas professoras, foi possível identificar inúmeros relatos ou depoimentos que marcam o início desta carreira em que estes profissionais ficam à mercê dos desafios e das dificuldades que Huberman (1992, p. 39) sintetiza explicitamente como etapa por ele chamada de "choque do real".

Trazemos breves discursos/colocações destas professoras iniciantes de uma escola municipal, obtidos por meio da aplicação de questionário semiestruturado. Os participantes explicitaram suas angústias, inseguranças, medos e dificuldades no início de sua carreira profissional ou o que Huberman (1992, p. 39) chamou de "estágio de sobrevivência" e de "descoberta".

Ao serem questionadas se o início da carreira delas foi marcado por dificuldades, desafios, angústias e também descobertas, aprendizados e realizações, as docentes afirmaram que sim. Segundo a professora Pilar, o início de sua carreira:

Foi marcado por diversos sentimentos, ora angústia/ revoltas e ora aprendizagens/realizações e foi desenvolvido com força de vontade e bastante confiança. Esses sentimentos representam algo arraigado e nesse momento, torna-se aparente diante da realidade, justamente no que "colocamos" em prática a teoria encontrando então, diversos obstáculos que ora lhe tornam capaz e, em outros momentos geram angústia.

Diante da fala da professora, é possível destacar que neste período se coloca em questionamento todo o conhecimento "adquirido" no curso de formação, conforme sintetiza Franco $(2000$, p. 34) “[...] no período inicial da carreira docente todo o referencial teórico aprendido na graduação é posto à prova".

Quanto à entrada na carreira docente, conforme explicitamos por várias vezes, este é um momento importante no processo de identidade assim fundamentado em Tardif (2002, p. 11) “[...] é período realmente importante na história profissional do professor, determinando, inclusive, seu futuro e sua relação com o trabalho".

Segundo a professora Alícia:

O início é sempre difícil, o medo de começar é inevitável. Quando somos rotulados "novatos" é bem pior, pois as veteranas (os) acham ou pensam que somos incapazes. Porém, com o tempo nos adaptamos pois adquirimos experiências com a rotina e nos sobressaímos cada vez mais.

Diante desta fala, citamos Junior (1984, p. 96) que afirma "Não é demais lembrar a importância dos estabelecimentos de ensino que recepcionam os professores em início de carreira, oferecendo-lhes condições adequadas ao bom desempenho de suas atividades profissionais". 
Em conformidade e abrindo a possibilidade de discussão sobre o pensamento acima, citamos Pimenta (2005, p. 29) que em suas colocações fala do processo de troca de informações, discussões e análise cotidiana da escola entre o professor iniciante e o "experiente", que atua por mais tempo no espaço escolar, pois poderia haver ação x reflexão x ação e posteriormente a prática por sua vez seria transformadora. A autora afirma que "[...] os professores vão constituindo seus saberes com praticum, ou seja, aquele que constantemente reflete na e sobre a prática".

Sobre a afirmação da professora Alícia, vale destacar Mariano (2012, p. 89) que faz afirmações sobre o papel e a responsabilidade deste professor que está sendo inserido neste âmbito escolar, pois ele “[...] deve responsabilizar-se, sozinho, pela sua aprendizagem e desenvolvimento profissional, bem como pelo aprendizado de seus alunos".

Os rótulos e os estereótipos são muitas vezes sentimentos marcados negativamente no trabalho e no processo de adaptação dos professores iniciantes nos contextos escolares, pois frases como "está fazendo isto só porque é novato", "daqui uns dias você cansa", "não vale a pena fazer tudo isto! " e "quer aparecer” que são ouvidas muitas vezes quando o docente está desempenhando um bom trabalho, ou melhor, quando está buscando melhorar enquanto profissional, contudo, para fortalecer esta discussão, trazemos o pensamento de Brostolin e Oliveira (2013, p. 45) que, sobre a relação do professor iniciante com os colegas de trabalho já “estabilizados”, salientam que "Às vezes, até mesmo os colegas de trabalho se voltam para o iniciante com rispidez, falta de companheirismo e parceria, dificultando o relacionamento no ambiente escolar e ainda mais o processo inicial da carreira".

Fundamentados nesta ideia, colocamos aqui também a fala da professora Marcela: “A gente aprende no dia a dia, você pode trabalhar com pessoas com mais experiência e é muito bom. Umas te ajudam, outras te prejudicam, é uma variedade".

A professora Rafaela, ao relatar seus desafios, cita que se sentia "estranha" ou "intrusa" naquele ambiente (escolar):

Nada foi fácil no início e parecia que eu estava sendo uma intrusa naquele ambiente. Senti uma insegurança diante dos meus alunos (as) e as colegas da escola diziam que todo aquele entusiasmo que trazia logo se acabaria. Minha autoestima ficou péssima. Durante semanas percebi que estava muito mal [...].

Percebe-se que o sentimento de pertencimento como profissional docente ainda não tinha sido alcançado por essa professora e, por isso, houve o estranhamento com relação ao espaço escolar.

Recorrendo a Huberman (1992), analisamos que essa professora passou pelo processo que o autor chama de "choque da realidade", "choque real" e/ou o "confronto" do ambiente 
BORGES, M. C..; SANTOS, P. V.

escolar. Porém, mais adiante, na fala da mesma professora citada anteriormente, percebe-se que ela conseguiu vencer as dificuldades e seus medos pelo processo de "descoberta" que, segundo o autor, é o processo de "sentir- se dentro", ou seja, neste estágio ela se sentiu na responsabilidade de ter sua sala, seus alunos, o que a ajudou na transposição das barreiras, inseguranças e críticas. Ela conclui sua fala afirmando: "Percebi que estava sendo manipulada, deixando de existir aquela professora que pensava na melhor metodologia para alcançar uma aprendizagem satisfatória. Foi então que cheguei no outro dia na escola sendo eu mesma".

Por políticas equivocadas de organização da escola na distribuição das turmas e designação de professores, estes professores são geralmente colocados em turmas "difíceis", heterogêneas e com alunos em condição de repetência escolar. São colocados à mercê da sorte e a professora Ana Emília levanta isto, claramente, em seu discurso:

[...] o que mais me marcou foi quando um aluno disse que me mataria e todos os dias ele me ameaçava. Era como matar um "leão" por dia, nesse relacionamento com esse aluno. Muitas vezes eu sentia dores não só no corpo, mas me sentia impotente, pensava muito em desistir de tudo.

Em consonância com este pensamento, Lima (2004, p. 96) afirma que "O problema se agrava quando às professoras iniciantes são atribuídas as turmas mais "complicadas" e "problemáticas", pois as profissionais que já têm pontuação elevada na carreira são, em geral, premiadas com as "melhores" turmas".

Segundo Brostolin e Oliveira (2013, p. 47) os confrontos neste primeiro contato, lamentavelmente, caso deem resultado negativo, poderão moldar a prática. Estas autoras explicitam:

Por sua inexperiência e os diversos conflitos presentes nesta fase inicial entre o que é o idealizado na formação e a realidade que é enfrentada na sala de aula, o professor padronizará sua forma de ensinagem, não levando em consideração a diversidade que há na individualidade do aluno.

Contudo, neste trabalho não consideramos que esta perspectiva ocorrerá em todas as ações dos professores principiantes, isto é, como uma verdade indiscutível, pois afinal, cada indivíduo traz consigo suas concepções e cada um, possivelmente, lidará de forma diferente com estes desafios e angústias.

Ao serem questionadas sobre o que ficou falho na sua formação inicial, as professoras afirmaram a necessidade de terem mais prática nos cursos de formação por acreditarem haver muita teoria. De acordo com a professora Laís, temos a seguinte afirmação: "acho que teria que ter muita prática para não chegarmos a uma escola despreparados”. Para analisarmos esta afirmação, citamos Cavaco (p.164), quando afirma que, diante da "Necessidade de construir 
respostas urgentes para situações complexas que enfrenta (...) filiam em modelos tradicionais, esquecendo mesmo propostas mais inovadoras que teoricamente defendera".

Os professores iniciantes, ao se depararem com inúmeros desafios e diante da realidade perplexa e crítica, normalmente não conseguem fazer a práxis, pois se veem "perdidos" diante do sistema educacional e da realidade encontrada.

No que tange a relação teoria e prática, grande parte das professoras depoentes disseram ser esta a "falha" na sua formação acadêmica, denunciando uma dicotomia entre ambas. Neste sentido, a professora Marcela assevera “[...] a falha na minha formação foi que o que você vê na sala de aula, você não vê na faculdade”. Diante desta colocação, citamos Brostolin e Oliveira (2013, p. 43) que afirmam “[...] ainda hoje, o maior problema na formação de professores está em fazer da teoria e da prática segmentos indissociáveis". Nessa perspectiva, citamos, ainda, Mariano (2012, p. 88) que também discute as dificuldades destes professores ao estabelecerem sua ação no âmbito escolar, pois "Não se encontra a percepção de que ambas devam caminhar lado a lado [...] Assistimos, assim, a um divórcio entre pensamento e a atuação docente". E, por fim, trazemos a contribuição de Ercolin, et al (2012, p. 2) "O aluno escolhe a profissão docente devido a inúmeras motivações, porém, a maioria tem uma visão idealizada do que é ser professor, como funciona uma escola e o que esperar dos alunos".

Não é objetivo neste trabalho discutir com profundidade o problemático distanciamento entre a teoria e a prática, pois percebemos variedade de ideias ou mesmo controvérsias A fim de exemplificar esta diversidade, vale destacar a afirmação da professora Elisa:

Não percebo muitas falhas entre o que tive na minha formação e o que encontrei quando cheguei à realidade da sala de aula. $\mathrm{O}$ embasamento teórico que tive foi bastante considerável e válido, as experiências vividas e os estágios realizados também. Mas creio que, querendo ou não, quando estamos exercendo a docência, principalmente no início, a teoria é um pouco diferente da prática. No entanto, com uma boa formação, pode-se ter um maior ângulo de possibilidades em determinada situação.

Entretanto, Pimenta (2005, p.15) afirmou que repensar a formação inicial e contínua, a partir da análise das práticas pedagógicas e docentes, tem se revelado uma das demandas mais importantes desde os anos 90, o que também demonstram as pesquisas de Cunha (1989); Zeichner (1993); Perrenoud (1994), Pimenta (1994); André (1994); Garcia (1994); e Benedito (1995). Pesquisas mais atuais como a de Gatti \& Barreto $(2009,2011)$ também confirmam a necessidade de maiores investimentos na melhoria da qualidade da formação de professores.

Assim, finalizando esta discussão, ressaltamos que o objetivo deste estudo não se resume nesta problemática, pois o que nele discutimos é a colocação das professoras iniciantes diante da sua experiência no âmbito escolar. 
A dificuldade vivenciada por estes professores iniciantes está configurada em inúmeros depoimentos. Podemos dar como exemplo, o da professora Marcela que fala sobre um dado ainda não apresentado pelas outras professoras, que a marcou como dificuldade e como experiência desafiadora no início da docência. A depoente afirma que ao ser contratada:

Comecei com grandes desafios e muitas dificuldades, por ser uma funcionária contratada e por expor ideias novas. Fui muito pautada (criticada ou questionada) por alguns superiores. Para quem está iniciando em rede pública, ou seja, na escola, pelo menos no meu caso, é muito complicado.

Diante desta fala, podemos afirmar que estas "barreiras" vivenciadas pelos profissionais iniciantes podem marcar, ou até mesmo abalar, sua postura profissional, pois, pelo simples fato de não poder expor suas ideias, ou até mesmo colocar em ação sua prática, este profissional passará por uma forte repressão e sentimento de não pertencimento. Ficará sem apoio, conforme afirma Ercolin, et al (2012, p. 5) "Sem estar ainda adaptado à nova instituição, sem sentir o apoio dos colegas professores com anos de casa, tal sofrimento pode provocar abalos à construção do perfil do docente".

Ainda sobre os desafios do professor iniciante, podemos citar a fala da professora Elisa:

\begin{abstract}
Acredito que o início da carreira docente de todos é marcado por vários sentimentos. No meu início tive dificuldades porque comecei em uma escola no meio do ano letivo e a sala de aula era de um contexto que já vinham dizendo ser a "sala mais difícil da escola". Então, seria um desafio por considerar como seria meu trabalho dada a realidade. Em inúmeras vezes fiquei angustiada porque o que planejava não alcançava o objetivo para alguns alunos, mas a persistência foi minha companhia constante. Ao longo dos dias percebi que tive muitas aprendizagens na relação professor-aluno que estabelecia com eles. E a realização veio posteriormente, quando fui me considerando mais experiente.
\end{abstract}

Ao observar as considerações da professora, percebe-se que ela confrontou a realidade, isto é, sobreviveu entre os erros, acertos, angústias e complexidade da inexperiência escolar.

Tendo em discussão o pensamento acima, citamos Reis (2012, p. 6) que, sobre o início profissão docente, afirma: "O início da carreira docente permite a percepção de que o professor também precisa aprender para ensinar, precisa conhecer seus alunos e a escola para propor atividades que partam do contexto de vivência dos alunos e da realidade por eles conhecida".

\title{
4.3 As aprendizagens significativas
}

Por fim, apontamos as aprendizagens atribuídas neste contato inicial de inserção no âmbito escolar que as professoras julgam como momentos significativos e importantes na sua construção identitária profissional. 
Ao serem questionadas sobre as aprendizagens adquiridas neste primeiro momento de inserção/experiência, as oito docentes, de forma unânime, afirmaram terem tido experiências exitosas e aprendizados significativos e importantes, alguns dos quais, passamos a ilustrar brevemente.

A professora Pilar afirma que uma das formas de aprendizagens adquiridas durante seu processo de inserção no âmbito escolar foi a "maturidade, conhecimento, posicionamento do eu como docente, fazendo meu papel naquele espaço”. Diante de tais colocações, percebemos que, pela responsabilidade estendida aos professores iniciantes, aparece a exigência de maior maturidade e postura mais consciente diante das inúmeras circunstâncias.

Já a professora Ana Emília foi breve em seu posicionamento. Porém, expôs seu posicionamento como "várias aprendizagens":

Ser dinâmico, saber organizar atividades diferenciadas de acordo com as dificuldades de cada discente"; [enquanto Rafaela afirma] "posso dizer que amadureci minha formação e consegui autonomia para buscar as melhores práxis. Percebi que apesar de todas as barreiras encontradas, fez-me crer que ser uma educadora é muito mais que cumprir quatro horas diárias, é dedicação e muita motivação.

Se verificarmos as falas e postura das docentes, podemos perceber que nas entrelinhas das suas falas está "o fazer professor" porque diante da prática há a demonstração do amadurecimento das ideias e a autonomia diante de sua formação e profissão.

Foi possível perceber que apesar das dificuldades, medos, anseios, inseguranças e crises enfrentadas no início da carreira profissional, elas assumiram também ter havido aprendizagens diante desta "etapa", "fase" ou "ciclo". Nesse enfoque, trazemos a contribuição de Gabardo e Hobold (2011, p.88), que afirmam que "As primeiras experiências vivenciadas pelos professores em início de carreira têm influência direta sobre sua decisão de continuar ou não na profissão porque esse é um período marcado por sentimentos contraditórios”.

Salientamos que muitos desistem ou que até mesmo abandonam a carreira docente por não conseguirem se adaptar ou superar as barreiras e dificuldades emergidas neste instante da vida profissional, conforme sintetiza Franco (2000, p. 35):

Não são raros os casos de professores que abandonam o magistério logo no início da carreira por não conseguirem gerenciar seus dilemas, como também não são poucos os que continuam, às vezes por falta de opção profissional, e que desenvolvem um sentimento de incompetência.

Algo preponderantemente positivo nas colocações das professoras foi a questão de escolha da profissão docente, uma vez que todas elas declararam que estão convencidas de que estão atuando na área almejada. As professoras também afirmaram terem projetos para o 
aperfeiçoamento da profissão docente, dentre os quais podemos citar as seguintes especializações: supervisão, orientação, mestrado e doutorado, dentre outros. Ressaltamos que apenas uma das oito professoras (Ana Emília) está cursando pós-graduação, lato sensu, em Psicopedagogia.

Ao solicitarmos que elas destacassem o que mais as marcaram como professoras iniciantes vieram à tona inúmeros acontecimentos e, dentre estes, podemos elencar alguns positivos e outros negativos.

A professora Pilar demonstrou satisfação e superação do momento de "sobrevivência" citado por Huberman (1992), pois, segundo ela, o que mais marcou seu início como professora foi:

A capacidade. Sendo eu como professora iniciante em uma turma rotulada como "terríveis", consigo então concluir aquele ano/série com pontos positivos e me sentindo realizada, mediadora do conhecimento". Porém, a professora Ana Emília destaca que "foi no ano passado que tive que assumir uma sala dita como problema, sendo minha primeira sala, onde os discentes tinham uma resistência à minha pessoa e demorou muito para que eles me aceitassem. Isso foi muito difícil, pois era uma sala sem disciplina, eu não poderia ser muito "boazinha" sendo, na maioria das vezes, rígida.

Em consonância ao pensamento acima, Brostolin e Oliveira (2013, p. 46) sintetizam:

As mudanças de comportamentos são acompanhadas, principalmente, por transformações ocorridas dentro da sala de aula. Diante da indisciplina dos alunos, o professor se esforçar para manter a sala controlada e não causar maiores problemas com a coordenação e direção da escola.

Com vistas a fortalecer esta discussão de experiência marcante no início da carreira, salientamos, ainda, o que diz a professora Rafaela:

Teve um dia na sala de aula que me marcou muito. Uma aluna de oito anos estava inerte diante da sala. Parecia estar em outro mundo. Então, esperei a hora do recreio e pedi que ficasse na sala. Perguntei o que acontecia, por que tanta tristeza. Meu Deus! Quando começou a falar, fiquei paralisada, não sabendo o que fazer. Disse que tinha dias que não dormia direito, seus pais estavam brigando muito e sua mãe tinha que dormir no carro com ela e seus irmãos, pois seu pai era muito mau. Aquele momento foi crucial para minha formação, pois sabia que poderia encontrar momentos críticos como esse da minha aluna, mas busquei ajudá-la e consegui falar com sua mãe. Quando comecei a explicar o porquê do nosso encontro, chorou muito e me abraçou. Para uma professora de poucos meses de experiência, acredito ter entendido que não existe uma escola perfeita, alunos (as) programados, mas sim uma escola real que busca uma aprendizagem ideal.

Observando o relato das professoras, podemos compreender o que outrora afirmamos sobre estes profissionais iniciantes serem colocados em sala "difíceis". Nota-se, porém, que elas conseguiram superar a fase de "inserção" no âmbito escolar. Neste contexto, vale citar 
Huberman (1992, p.39), corroborando com as colocações das docentes. O autor declara: "traduz o entusiasmo inicial, a experimentação, a exaltação por estar, finalmente, em situação de responsabilidade (ter a sua sala de aula, seus alunos, o seu programa)".

Ressaltamos que, mesmo diante das discussões acima apresentadas sobre os "ciclos" e "fases", reafirmamos, com a fala da professora Laís: "Como foi bom ser acolhida na escola [...] aqui estou aprendendo e ensinado com amor". O que queremos dizer é que poderão ocorrer divergências de "recepção da carreira" docente, pois estas variam de cultura para cultura, local para local e de profissional para profissional, pois afinal não estamos tratando aqui de uma verdade absoluta e indiscutível.

Vale ressaltar que os professores trazem consigo inúmeras experiências, vivências, concepções, visões de homem/sociedade/mundo que possivelmente nortearão sua prática. Isso se torna mais importante ainda quando se trata de professor principiante, em um contexto em que este se vê em um emaranhado de informações e na busca por "acertos". Segundo as autoras Gabardo e Hobold (2011, p.88):

[...] os professores já trazem consigo muitas experiências sobre o ser professor, dessa sua própria trajetória como estudante, nas séries anteriores à formação inicial, bem como as novas vivências culturais que se engendram no espaço escolar e na sua interação com os colegas professores e estudantes.

Ainda sobre a profissão docente, podemos observar que os alunos levam consigo para os cursos de formação acadêmica ideias, marcas e levantamentos de conceitos sobre o ser professor. Entretanto, quando entram no âmbito escolar, são levados a fazer inúmeras e contínuas indagações sobre seu papel social, devido a uma diversificação de visões, isto é, enquanto alunado e, posteriormente, como professor. Nesse enfoque vale destacar Pimenta (2005, p. 20): “O desafio então posto aos cursos de formação inicial é o de colaborar no processo de passagem dos alunos de seu ver professor como aluno e ao seu ver-se como professor".

\section{CONSIDERAÇÕES FINAIS}

O estudo apresentado buscou analisar e conhecer quem é o professor iniciante dos primeiros anos do ensino fundamental da escola pública e quais são os desafios, conflitos e aprendizados no seu desenvolvimento profissional.

Pela análise da pesquisa e dos dados obtidos, concluímos ter alcançado resultados que nos levaram a confirmar nossas indagações e discussões que permearam todo este trabalho.

Os dados apresentados pelas professoras nos fizeram perceber que o início da carreira docente é marcado por dificuldades, medos, angústias, desafios, conflitos e aprendizagens, além 
BORGES, M. C..; SANTOS, P. V.

de ser um período que requer do professor amadurecimento e preparo para enfrentamento dos inúmeros dilemas.

Em conformidade ao quadro de profissionais pesquisado, foi possível perceber que os professores iniciantes objeto deste estudo - no seu perfil - são todas do sexo feminino com idades entre vinte e dois e trinta e sete anos, trabalham apenas em uma escola, cujo estado civil varia entre casadas, solteiras e divorciadas. Quanto ao tempo de atuação, este varia entre poucos meses a um ano. Voltamos a salientar que, para ir ao encontro do objetivo deste trabalho, procuramos entrevistar docentes com, no máximo, dois anos de atuação.

No que diz respeito aos desafios enfrentados, os relatos e depoimentos esclareceram o que podemos resumir em algumas palavras, tais como: medo, insegurança, angústia, conflitos, ausência de acompanhamento pedagógico, impactos com a realidade, resistência dos professores estabilizados e com maior tempo de carreira, a não associação da teoria e a prática, atuação em salas tidas como "indisciplinadas" e "difíceis", dentre inúmeros outros desafios.

Em relação aos seus aprendizados e desenvolvimento profissional, quanto às professoras principiantes participantes desta pesquisa, pudemos ter acesso a várias informações que demonstram seu crescimento profissional. Podemos citar, por exemplo, que houve maturidade de ideias, esforçaram-se para ser dinâmicas, compreender a realidade do discente e, a partir dela, conseguiram planejar e desenvolver suas aulas e vencer seus medos, anseios, dificuldades, dentre outras questões.

Ressaltamos que a vontade e o desejo dos professores iniciantes parecem fazer com que eles consigam um bom desenvolvimento em seu trabalho, pois sempre buscam a "melhor" maneira de compreender os alunos, levando em consideração especificidades para ensinar, além de repensar formas de melhorar, constantemente, o processo de ensino aprendizagem.

Percebe-se que muitas vezes as resistências destes professores que já se encontram no âmbito escolar por mais tempo acontecem simplesmente por estes profissionais principiantes não se acomodarem à realidade e à metodologia imposta tanto pelo sistema, quanto pela rede de ensino que, muitas vezes, é conservadora, tradicional.

Em síntese, a escola deveria prover momentos de assiduidade, receptividade, troca de informações, dinâmicas e discussões com estes professores iniciantes, bem como acolhê-los, dando-lhes total apoio e ainda fomentar programas de formação continuada que visem a vivência da docência. Estes programas deveriam considerar as teorias aqui apresentadas e discutidas, por sabermos que o processo inicial da carreira é que definirá as ações, a didática e a metodologia destes professores que, muitas vezes, são colocados à mercê da própria sorte, ocasionando desgaste de seus sonhos e certezas. Tal situação pode ser a desencadeadora da 
dicotomia entre a teoria e a prática que muitas vezes os professores julgam como sua principal dificuldade em meio às divergências iniciais. Espera-se que eles apresentem resultados instantemente e de forma eficaz, fazendo com que não encontrem meios de concretização de suas teorias e discussões já estudadas e defendidas. Deve-se ter em mente que eles têm um emaranhado de problemas para resolver.

Pela análise dos dados, leituras realizadas e pelos diálogos com inúmeros professores principiantes, percebe-se que eles são recém-formados e, como experiência escolar, têm apenas o estágio supervisionado obrigatório e programas e projetos de intervenção. Dessa forma, ao terem sua própria sala de aula, esbarram em barreiras e resistências que estão constituídas no próprio espaço escolar.

Um dos fatores que possivelmente poderia auxiliar estes professores seria a aproximação com os professores já "experientes" como forma de estabelecer diálogos nos momentos de angústias, dificuldades e aprendizagens. Por conseguinte, ambos aprenderiam simultaneamente.

Os professores iniciantes deveriam ser acolhidos e recebidos de forma positiva no âmbito escolar com oportunidades de discussão de ideias. Caso eles continuem sendo vistos como "intrusos", continuaremos a ter profissionais desistindo da profíssão, se sentindo angustiados por suas desilusões, sonhos e desejos, sendo gradativamente destruídos e passando por dificuldades, sem ter onde buscar auxílio. Por fim, serão deixadas marcas em sua carreira profissional que, por certo estarão associadas à sua atuação.

Como sugestões, "saídas" ou mesmo "soluções" para o enfrentamento de todos os desafios, medos e angústias dos professores iniciantes, ao assumirem uma sala de aula, apontamos:

- Maior parceria e compromisso com a formação do profissional docente, entre as Universidades e as Escolas de Educação Básica.

- Enfoque nas discussões sobre o professor iniciante, bem como seus desafios e aprendizagens ao serem inserido no espaço escolar.

- Análise sobre o universo significativo dos cursos de Pedagogia, isto é, em suas concepções e metodologias de ensino para que o profissional não se veja refém de uma formação superficial e distante da realidade educacional vigente e cotidianas das escolas.

- Superação das propostas dos cursos, indo mais além na grade curricular, tendo em vista a formação pela pesquisa, para que o graduando perceba a complexidade da realidade, mas saiba subsidiar e alicerçar suas ações subsequentes. 
Em estudos anteriores percebe-se a necessidade de os docentes fazerem um curso de graduação que possa sanar suas dificuldades e propiciar uma formação nova e crítica por haver evidências de lacunas na sua formação no que diz respeito às concepções do saber teórico e prático.

Os resultados desta investigação inspiram ou suscitam a necessidade de outras investigações em busca de melhor compreender a reestruturação dos currículos, estabelecer mais parcerias entre escolas da Educação Básica e da Universidade e de haver uma maior interação entre a teoria e a prática docente.

Concordando com Paulo Freire (1996), afirmamos que o processo de formação do ser humano é contínuo, pois o "inacabamento" do ser humano e sua inconclusão se prolongam pela vida toda. A presença humana no mundo não é de adaptação e nem de resignação. Devemos nos posicionar como seres de luta, de busca, de sujeitos que constroem e dirigem o rumo de sua história, pois enquanto há vida, há aprendizados e também esperança.

\section{REFERÊNCIAS}

BROSTOLIN, Marta Regina; OLIVEIRA, Evelyn Aline da Costa de. Educação Infantil: dificuldades e desafios do professor iniciante. Interfaces da Educação, Paranaíba, v.4, n.11, p. 41-56, 2013. Disponível em:

https://periodicosonline.uems.br/index.php/interfaces/article/view/520/486. Acesso em: 10 jan. 2017

CAVACO, Maria Helena. O ofício do professor: o tempo e as mudanças. In: NÓVOA, António (Org.). Profissão professor. Lisboa: Porto, 1995, p.155-177.

CHIZZOTTI, Antonio. Pesquisa em Ciências Humanas e sociais. 7. ed. São Paulo: Cortez, 2005.

DALBERIO, Oswaldo; BORGES, Maria Célia. Metodologia científica - desafios e caminhos. São Paulo: Editora Paulus, 2014.

ERCOLIN, Eliza Helena; SÓRIO, Walter Fernandes; PASSAES, Manoel F.; RODRIGUES, Norberto; PINTO, Tânia Cristina dos G. O professor iniciante: expectativas na licenciatura em pedagogia e a realidade na sala de aula. Revista Eletrônica de Divulgação Científica da Faculdade Don Domênico. 6. Edição, set. 2012.

ESTRELA, Maria Teresa. Viver e construir a função docente. Lisboa: Porto, 1997, p.51 - 80.

FONTANELLA, Bruno José Barcellos; RICAS, Janete; TURATO, Egberto Ribeiro. Amostragem por saturação em pesquisas qualitativas em saúde: contribuições teóricas. Cadernos de Saúde Pública. Rio de Janeiro, v. 24, n. 1, p. 17-27, jan. 2008. Disponível em: http://www.scielosp.org/scielo.php?script=sci_arttext\&pid=S0102-311X2008000100003. Acesso em: 22 nov. 2009. 
FRANCO, Francisco Carlos. O coordenador pedagógico e o professor iniciante. In: ALMEIDA, Laurinda Ramalho. BRUNO, Eliane Bambini; CHRISTOV, Luiza Helena. $O$ coordenador pedagógico e a formação docente. São Paulo: Loyola, 2000, p.33-36.

FREIRE, Paulo. Pedagogia da Autonomia: saberes necessários à prática educativa. 34 ed. São Paulo. Ed. Paz e Terra, 1996.

FREITAS, Maria Nivalda de Carvalho. Organização escolar e socialização profissional de professores iniciantes. Cadernos de Pesquisa, n. 115, p. 155 - 172, março/2002. Disponível em: http://www.scielo.br/pdf/cp/n115/a06n115.pdf. Acesso em: 10 jan. 2018

GABARDO, Claudia Valéria; HOBOLD, Márcia de Souza. Início da docência: instigando professores do ensino fundamental. Formação Docente, Belo Horizonte, v. 03, n. 05, p. 8597, ago/dez. 2011.

GARCIA, Carlos Marcelo. O professor iniciante, a prática pedagógica e o sentido da experiência. Formação Docente. Revista Brasileira de Pesquisas sobre Formação de Professores, v. 3, n. 3, ago-dez. 2010.

GATTI, Bernardete; BARRETO, Elba Siqueira de Sá; ANDRE, Marli Eliza Dalmazo de Afonso. Politicas docentes nos Brasil: um estado da arte. Brasília: UNESCO, 2011.

GATTI, Bernardete; NUNES, Marina Muniz Rossa (Orgs.). Formação de professores para o ensino fundamental: estudo de currículos das licenciaturas em Pedagogia, Língua Portuguesa, Matemática e Ciências Biológicas. São Paulo: FCC/DPE, 2009.

GUARNIERI, Maria Regina. Tornando-se professor: o início na carreira docente e a consolidação da profissão. São Carlos, 1996. Tese (Doutorado em Educação) - Centro de Educação e Ciências Humanas, Universidade Federal de São Carlos - UFSCar, 1996.

HUBERMAN, Michael. O ciclo da vida profissional dos professores. In: NÓVOA, António. Vidas de professores. Lisboa: Porto Editora, 1992, p.31-61.

IMBERNÓN, Francisco. Formação docente e profissional: forma-se para a mudança e a incerteza. 4. ed. São Paulo: Cortez, 2004.

LIBÂNEO, José Carlos. Reflexividade e formação de professores: outra oscilação do pensamento pedagógico brasileiro? In.: PIMENTA, Selma Garrido; GHEDIN, Evandro. Professor reflexivo no Brasil: gênese e crítica de um conceito. 2. ed. São Paulo: Cortez, 2002.

LIMA, Emília Freitas de. A construção do início da docência: reflexões a partir de pesquisas brasileiras. Educação, Santa Maria, v. 29, n. 2, p. 85-98, 2004.

MARIN, Alda Junqueira. O curso de pedagogia em foco: fragilidades constantes e urgências da formação. In: ENCONTRO NACIONAL DE DIDÁTICA E PRÁTICA DE ENSINO, ENDIPE XVII, Fortaleza, 2014. Anais... Disponível em: http://www.uece.br/eventos/xviiendipe/. Acesso em: 24 jan. 2015.

MARIANO, André Luiz Sena. A aprendizagem da docência no início da carreira: Qual política? Quais problemas? Revista Exitus, v. 2, n 1. jan. /jun. 2012. 
MORAIS, Régis de. Um abominável mundo novo? O ensino superior atual. São Paulo: Editora Paulus, 2011. (Coleção Educação Superior).

VIEIRA JÚNIOR, José Marcos. A construção do processo de aprendizagem profissional de professores iniciantes, Viçosa, 2013. Dissertação (Mestrado em Educação) - Universidade Federal de Viçosa, 2013.

PIMENTA, Selma Garrido (Org.). Formação de professores: identidade e saberes da docência: In: Saberes Pedagógicos e atividade docente. 4 ed. São Paulo: Cortez, 2005.

PIMENTA, Selma Garrido. A formação de professores para a Educação Infantil e para os anos iniciais do Ensino Fundamental: análise do currículo dos cursos de Pedagogia de instituições públicas e privadas do Estado de São Paulo. In: ENCONTRO NACIONAL DE DIDÁTICA E PRÁTICA DE ENSINO, ENDIPE XVII, Fortaleza, 2014. Anais... Disponível em: http://www.uece.br/eventos/xviiendipe/. Acesso em: 24 jan. 2015.

REIS, Marciene Aparecida Santos. Professores Iniciantes: narrativa como experiência de constituição no cotidiano da escola. In: IX Seminário de Pesquisa em Educação da Região Sul - ANPED SUL, 2012. Anais... Disponível em:

http://www.ucs.br/etc/conferencias/index.php/anpedsul/9anpedsul/paper/viewFile/115/429. Acesso em 10 jan. 2018

SOUZA, Dulcineia Beirigo de. Os dilemas do professor iniciante: reflexões sobre os cursos de formação inicial. Saber Acadêmico, n 08, dez. 2009.

TARDIF, Maurice. Saberes docentes e formação profissional. Petrópolis, RJ: Vozes 2002.

ZEICHNER, Ken. Repensando as conexões entre a formação na universidade e as experiências de campo na formação de professores em faculdades e universidades. Rev. Educação. Santa Maria. V. 35, n.3, p 479-504, set/dez. 2010. Disponível em: https://periodicos.ufsm.br/reveducacao/article/view/2357. Acesso em 10 jan. 2018.

\section{SOBRE OS AUTORES}

Maria Célia Borges é Doutora em Educação pela Pontifícia Universidade Católica de São Paulo (PUCSP), com Pós-doutorado pela Faculdade de Educação da Universidade de São Paulo (FE-USP). É professora do Curso de Pedagogia e Licenciaturas no Instituto de Ciências Humanas do Pontal. É docente do Programa de Pós-graduação stricto sensu na Educação da Universidade Federal do Triângulo Mineiro (UFTM) e na Faced, Universidade Federal de Uberlândia (UFU).

E-mail: marcelbor@gmail.com; mariacelia@ufu.br

Paulo Vinicius dos Santos é graduado em Pedagogia pela Universidade Federal de Uberlândia e professor e regente no Ensino Fundamental.

E-mail: paulo.santos94@hotmail.com 